\title{
Introduction to the Benchmark Challenge on SICE Engine Start Control Problem
}

\author{
Akira Ohata*. Junichi Kako** \\ Tielong Shen $* * *$. Kazuhisa Ito**** \\ * Power Train Control Div. Toyota Motor Corporation, Shizuoka, Japan, \\ (Tel : +81-55-997-7547; e-mail: ohata@control.tec.toyota.co.jp ). \\ ** Power Train Control Div. Toyota Motor Corporation, Shizuoka, Japan, \\ (e-mail:jun@kako.tec.toyota.co.jp) \\ *** Department of Mechanical Engineering, Sophia University, Tokyo, Japan, \\ (e-mail: tetu-sin@sophia.ac.jp) \\ **** Department of Mechanical Engineering, Tottori University, Tottori, Japan, \\ (e-mail:kazu-ito@mech.tottori-u.ac.jp)
}

\begin{abstract}
The speed control during cold start for SI engines is a challenging topic due to the difficulties in handling the dramatic change of the engine dynamics. The SICE Research Committee on Advanced Powertrain Control Theory provides a V6 SI engine model and the benchmark problem of cold start control focusing on the engine speed behavior when the engine model starts. The control design specification is explained in detail and a traditional control is also shown in this paper. Finally, a brief review is given on intermediate results of the challengers.
\end{abstract}

\section{INTRODUCTION}

The automotive industry has been confronted by serious social problems, the global warming, the air pollution, the energy crisis and the traffic safety. Control technologies have been continuously expanded to encounter these issues. That makes powertrain controls highly sophisticated and complex. Therefore, it has been becoming difficult to develop the reliability within the reasonable time and resources. In addition, the development period should be shortened to provide new technologies to the market immediately.

From the above situation, the collaboration between the academic society and the automotive industry has been getting important. However, the communication between both has been inefficient. It hasn't been easy for the academic society to know the requirements from the automotive industry. On the other hand, it has been difficult for the automotive industry to know what control technologies are applicable to their needs. Many universities have no engine test facility and there has been no good engine model shared among researchers. The situation has prevented university's involvement in the area.

The SICE Research Committee on Advanced Powertrain Control Theory was established in 2006, to contribute to reinforce the collaboration between them. In order to change the situation, we provided a gasoline engine model and a benchmark problem of control technologies. The problem is to start the engine model as starting an actual engine. Cold engine start is one of the most important problems in automotive engine control because nothing happens before starting the engine. The intermittent phenomena due to the engine cycle appear more strongly at lower engine speed and almost all of the harmful tail pipe exhaust gases are emitted during the short period after starting the engine. Moreover, the stably and smoothly engine restart is highly required so that $\mathrm{HV}$ vehicles stop the engine to save fuel at the low speed.

\section{PROVED ENGIEN MODEL}

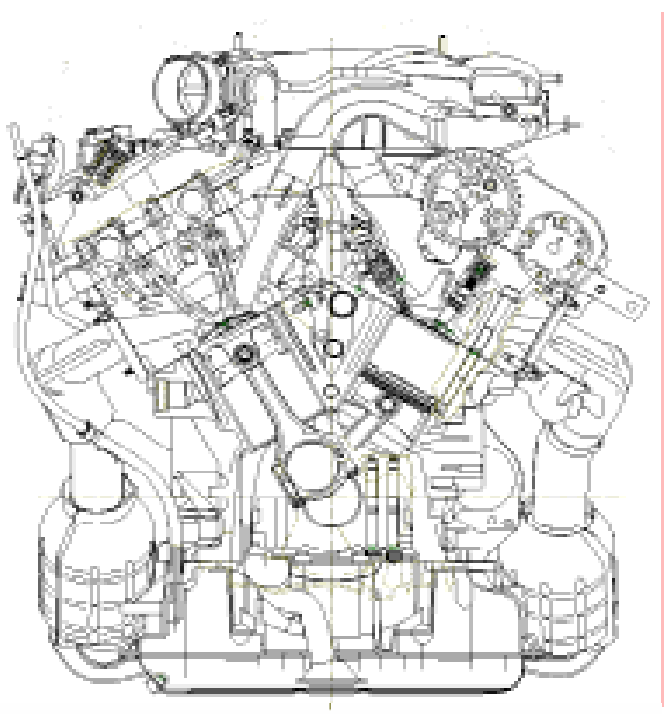

Fig.1 targeted V6 SI engine

Fig.1 shows the sketch of the targeted 3.5liter V6 SI engine that has the gasoline injection at each intake port. We devised to make the same situation, which the developers in the automotive industry are confronted with. The provided engine model is constructed complying with physical 
principle as possible as it can so that the challenger's physical considerations can be effective. Thus, projection method is applied to the mechanical portion and the modelling method based on the relevant conservation laws is applied to the other portions. The adjustment of the model parameters was nearly not performed to minimize the error between the experimental and simulated data. Therefore, the model is a conceptual one.

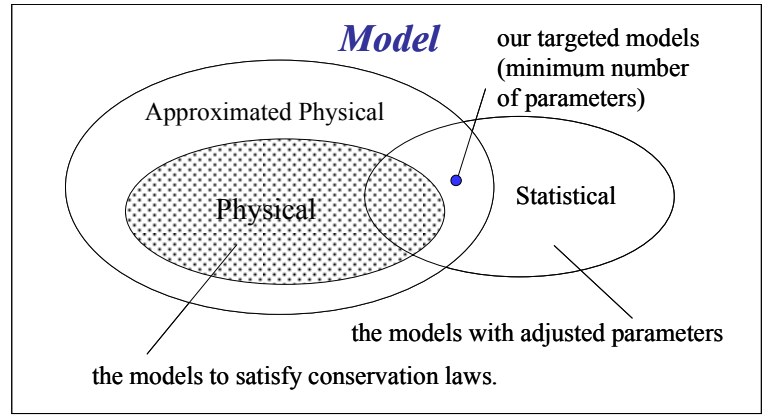

\section{Fig. 2 concept of plant modelling}

Fig. 2 shows the concept of plant model. Here, we think lamped parameter model for control design. The universal set of the models describes the relationship among the inputs, the disturbances and the outputs. Physical model is defended as the ones that meet the relevant conservation laws and statistical model is defended as the ones that have the parameters adjusted by using the experimental data. The constraint of the conservation laws is relaxed because they are sometimes too strong for practical usages. It is considered that a relaxed model is around the physical model. Thus, it is called approximated physical model. The targeted model for control design is usually in the set of approximated physical model. However, it is very difficult for the challengers to understand the physical background of approximated physical model. Thus, we decided that the model for the benchmark problem belongs to a set of physical model.

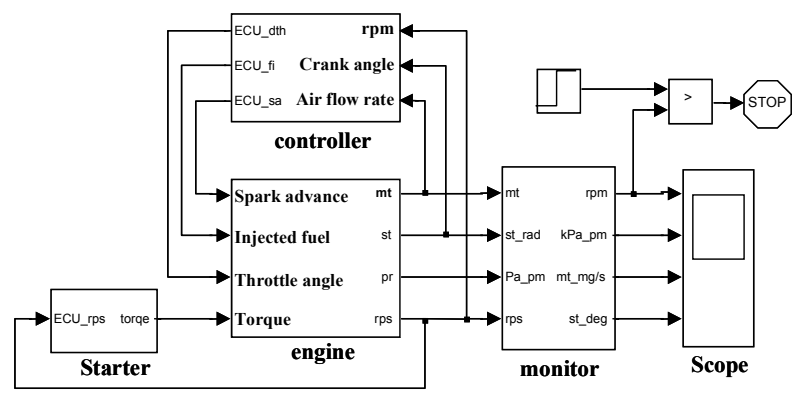

Fig. 3 top layer of the provided model

Fig.3 shows the top layer of the provided model described with Simulink ${ }^{\circledR}$. The challengers can access to any portions of the model and any model parameters. However, there is no document explaining the detail of each block although the brief explanation of the model was given at the beginning of the challenges. This situation is quite similar to the one that an engineer given an actual engine encounters. Thus, the challengers must analyze the engine model first. It is also included in our intention. We would like to see their process as well as their control design. Our interests are not only what control they design but also how they design their control.

As shown in Fig.3, the provided engine model consists of the engine block, the control block and the starter motor block. The inputs of engine are the throttle angles, the amount of the injected fuel mass and the spark advance of all the cylinders. The crank angle, the engine speed and the air flow rate through the throttle valve are fed to the controller. The inputs and the outputs of the controller are specified in the control block and can't be changed by a challenger. The challengers must draw their controllers in the control block. The scope block is added to monitor the engine speed, the intake pressure, the air flow rate through the throttle valve and the crank angle of the cylinder 1 .

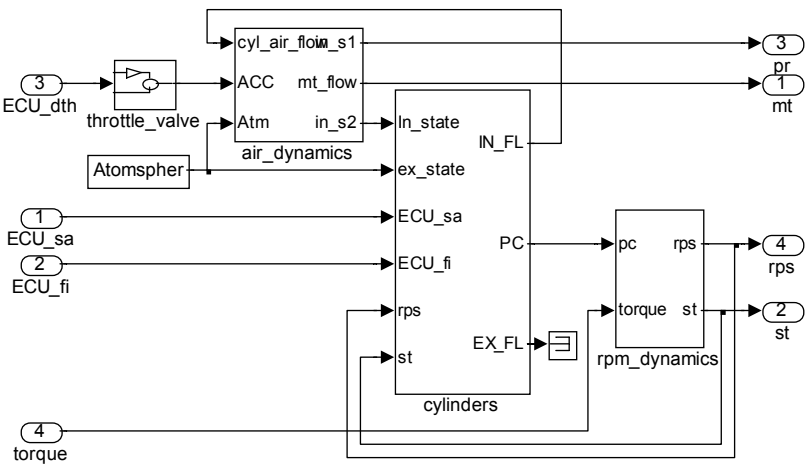

Fig. 4 Inside of the engine block

Fig. 4 shows the inside of the engine block. It consists of the air dynamics block corresponding to the intake chamber, the cylinder block and the block for the mechanical portion of the crank system. The throttle valve is directly connected with the atmosphere. The cylinder block describes the right and the left banks of the engine and each bank has three cylinders. The behaviour of the fuel in the inlet port and the intake valve of each cylinder are considered. The cylinder pressure profile with the crank angle is calculated and the air flow rates through the intake and the exhaust valves are also calculated with the crank angle. Each exhaust port opens to the atmosphere. The crank shaft isn't connected with the transmission.

Other version of the model is provided so that the challengers can understand the cold start engine speed behaviour when the throttle angle, the spark advance and the injected fuel mass are constant. It can be useful for the challengers to understand the purpose of the designed control in the benchmark problem well.

Fig.5 shows an example of simulation results after the engine starts. The upper figure shows the engine speed excursion and the bottom figure shows the pressure profile of each cylinder. The engine speed fluctuation during each engine cycle appears in the upper figure. The cylinder pressures, the piston inertias and so on cause it. Before firing, the starter motor controls the engine at $250 \mathrm{rpm}$. The air fuel ratio, the throttle angle and the spark advance are constant. The air fuel ratio is the stoichiometric. This means 
the fuel mass in the cylinder is calculated from the induced air mass during the intake stroke as shown by the equation (1).

$$
\text { fule mass }=\frac{\text { air mass in the cylinder }}{14.5}
$$

The engine speed rises rapidly after the ignition, comes down and gradually converges to 650rpm. The steep overshoot of the engine speed is the common phenomenon when an engine starts.

The other model for validating the robustness of the developed controllers is also provided. The initial crank angle is the top dead centre in the previous one. However, it depends on the crank angle when the engine stopped and it is affected by various factors, for examples the friction torque, the engine speed when the ignition is turned off. The battery voltage changes the engine speed during the cranking period. The characteristic of the fuel evaporation highly affects the air fuel ratio control. The cold start control must be evaluated on such the various conditions.
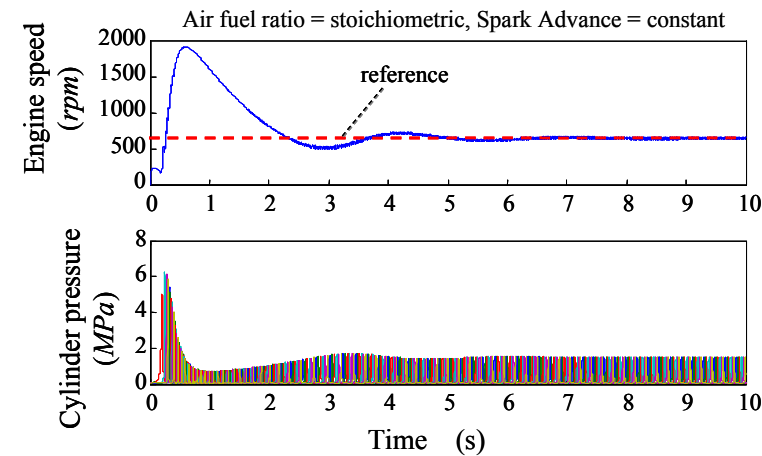

\section{Fig. 5 an example of simulation results}

\section{BENCHMARK PROBLEM}

The benchmark problem is to start the engine model and to regulate the engine speed at $650 \mathrm{rpm}$ immediately. The requirements are illustrated in Fig.6. The dotted line is the reference of the engine speed control. The engine speed must be confined in the area not hatched.

The requirements for the steady state are the followings.

(a) The closed loop is stable.

(b) The engine speed converges to 650rpm.

(c) The engine speed reaches $600-700 \mathrm{rpm}$ within $1.5 \mathrm{~s}$.

The requirements for the transient condition are as follows.

(d) The overshoot must be sufficiently suppressed.

(e) Hunting must not appear.

In the case of Fig. 6, only the requirement (a) and (e) are fulfilled. Fig. 8 is another example of the evaluations. It fulfils almost all requirements although the performance for the requirement (b) should be improved.

The following requirements for the robustness are added.

The requirement for the steady and the transient conditions must be fulfilled with the variations of the initial crank angle, the friction torque and the fuel evaporation characteristic.

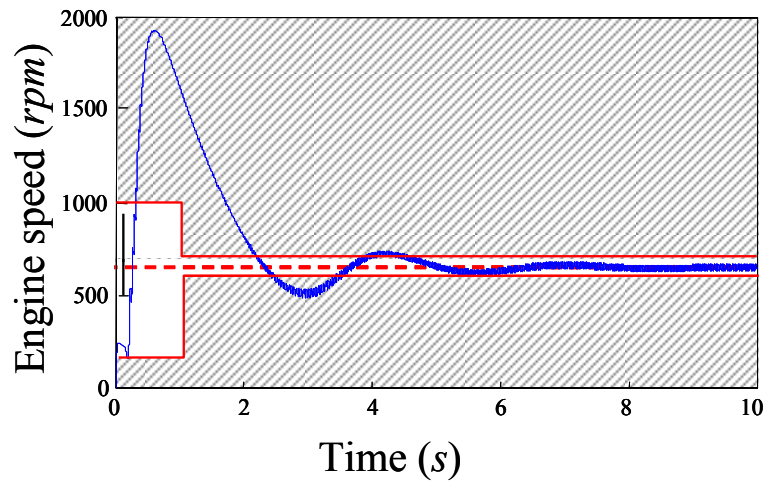

Fig.6 an example of evaluation

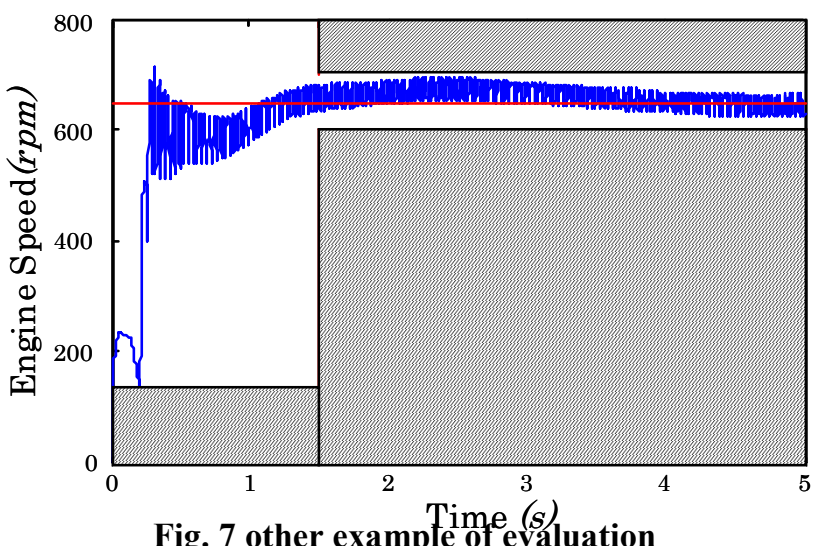

\section{DISTINCTIVE FEATURES OF THE PROBLEM}

Fig. 8 shows the behaviour that makes starting the engine difficult. The engine model has the state transition between "firing" and "misfiring" as shown in Fig.8. The mixture gas in the cylinder ignites when the air fuel ration is the following range.

lower limit $\leq$ air fuelration $\leq$ upper limit

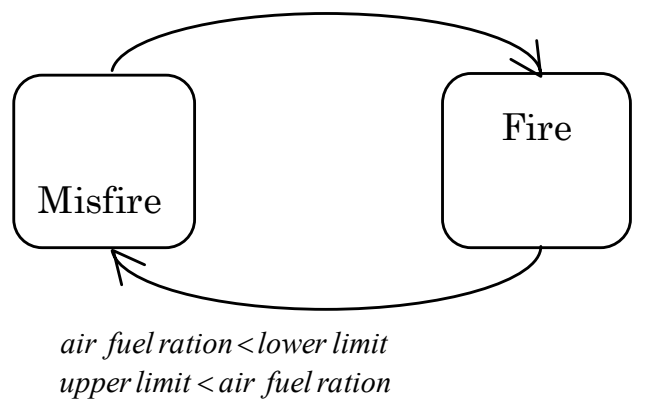

Fig.8 State transition of engine behaviour

It doesn't ignite when the above condition isn't satisfied. In the state of "firing", the engine is stable although the strong nonlinearity appears. In the state of "misfiring", the engine is unstable and reaches the engine stall. Thus, the key of the engine control is to keep the condition of "firing" given by the equation (2).

lower limit $\leq$ air fuel ratio $\leq$ upper limit 
Other important feature is the redundancy of the inputs to control the engine speed. The throttle angle, the fuel injection and the spark advance affect the engine speed. Thus, the assignment of each role is essential. Usually, the fuel injection is used to control air fuel ration at the stoichiometric accurately for exhaust emission, because its torque control range is limited. The throttle angle can control the engine speed in the wide range and highly economical although the response of the engine speed control is relatively slow compared with the spark advance. The spark advance is quickest way but affects the fuel consumption. Thus, the role of each input is as follows in the ordinal engine control.

(1) the fuel injection : air fuel ratio control

(2) the throttle angle : fuel consumption

(3) the spark advance :rapid engine speed control

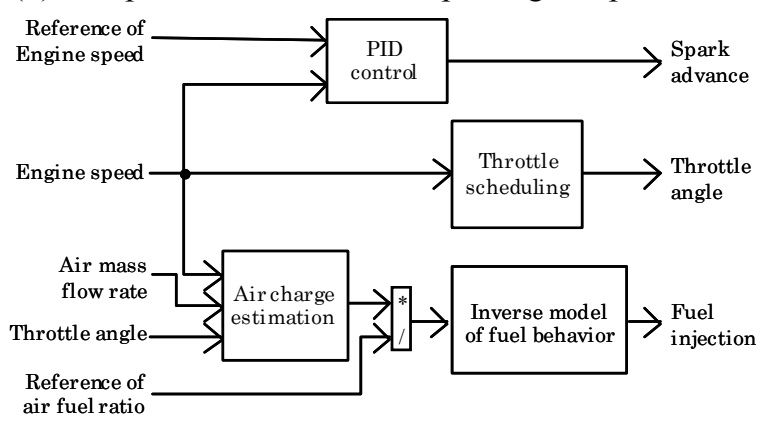

Fig.9 ordinal structure of engine control

Fig. 9 briefly shows a structure of engine control used by the automotive industry when starting an engine. The throttle valve control can be designed as a continuous time system but the fuel injection and the spark advance controls must be designed as discrete time systems. They are actuated every engine stroke. This can be translated as follows.

The engine model can be described by the following general form.

$$
\frac{d x}{d t}=f(x, u)
$$

Here, denotes the states and $u$ means the inputs.

$$
\frac{d x}{d \theta}=\frac{f(x, u)}{\omega}
$$

Where, $\theta$ is the crank angle and $\omega=d \theta / d t$ is the engine speed. Using the equation (4), the engine model can be transformed to the discrete crank angle system. However, $1 / \omega$ may be an issue at the lower engine speed. This means that we don't have the frequent occasions to actuate the engine. This is one of the reasons of the difficulty to suppress the engine overshoot. Thus, we have to relay on the feedforward for the purpose.

Fig. 10 shows the possible control strategy. It changes with time. This is other important feature of this problem although someone can take a time invariant control strategy. But, the time variant control strategy has the bases from physical phenomena. The discrete event feature exists behind the seen. Thus, it can be considered that the strategy is natural and fundamental for the problem.

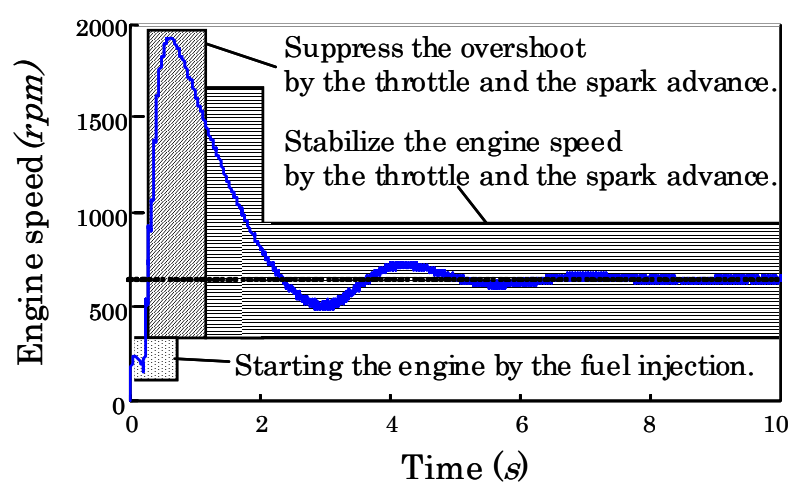

\section{Fig.10 the strategy of engine control}

From the above discussion, the distinctive features of this problem are summarized below.

(1) state transition between stable and unstable states

(2) redundancy of inputs

(3) continuous time and discrete event system

(4) time variant control strategy

(5) combination of feedforward and feedback

Thus, it can be considered that this problem is "complex". Here, "complex" means that it can't be solved by only one method and the combination of methods is required. For example, a few of advanced controls were applied to idle speed control. The control can be derived from the framework of the linear control design. Therefore, idle speed control is simple in this context. However, this problem can't be solved by only one framework and requires combining other methods. An engineer of the automotive industry is struggling to deal with this type of complexity. On the other hand, simple things are piled in the education of university. The direction is from simple to complex. But, as mentioned above, an engineer of the automotive industry is given a complex problem at the beginning. He must take the inverse direction, from complex to simple. This is the reason that we adopted this problem.

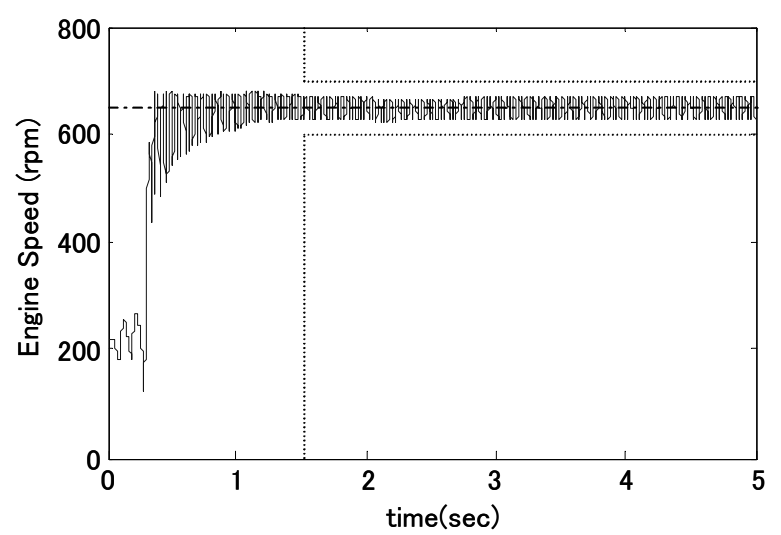

Fig. 11 an example of control results

Fig.11 shows an example of control results with the control structure shown in Fig. 9 according to the strategy shown in Fig.10. This result meets the requirements of the problem although a little improvement is still possible. However, the problem is still difficult because the robustness to the variations of fuel, engine setting and 
environment is highly required. To guarantee the reliability in the market place is tough problem. Usually, it takes huge time to complete it. Moreover, the requirements from the reliability and the exhaust gas emission control cause the trade off issue. Thus, the more efficient and accrete control designs are highly required.

\section{APPROACES OF UNIVERSITIES}

Seven challengers reported their intermediate results in the $36^{\text {th }}$ SICE Symposium on Control Theory at Sapporo, Japan on September $6^{\text {th }}, 2007$. All challengers succeeded to start the engine although some levels of the overshoot and the engine speed stability were seen in their results. Their approaches can be classified into the following classes.

A: analyzing the model to know the physical back ground and recreating the equations of the model

B: similar control design to the traditional approach with an advanced control methodology applied to a portion

$\mathrm{C}$ : trying to find the optimal input time sequence profiles and the combination with the feedback control around the profiles

D: simulation data based approach combined with the traditional engine control structure

E: reckless approach to use the state of "misfire"

We highly appreciate the effort of the challengers A who analyzes the engine model. It must be a very hard work. They have known that the engine model is very complex and has the discrete event feature and the strong nonlinearity. They couldn't find a theory directly applicable to the set of the equations. They will try to simplify the equations or to find a good way to deal with the model from computer science and information theory.

The challengers B adopt the control architecture similar to the existing one. That would be the most promising. The physical consideration seems to be very useful. Their advanced control seems to be able to improve the performance compared with the existing one and also seems to demonstrate the power. One of them analyzed the measurement and actuation timings very carefully. That is very important in the control design.

The challengers $\mathrm{C}$ are still struggling to get a good result although they succeeded starting the engine and stabilizing the engine speed. The optimization may be caught by a local minimum and not reach the global optimal input profile. They have the problem when the feedback starts because it doesn't work well during the condition of "misfiring". The approaches are very attractive because it can clarify the optimal operation of the throttle, the fuel injection and the spark advance and can be expanded to the case in which more constraints are added, for examples, warming up the catalyst and the minimizing the $\mathrm{HC}$ exhaust gas emission. They tried to optimize the fuel injection and the spark advance profiles under the condition of the constant throttle angle by manually. Other challenger obtained the three input profiles at the same time by a numerical optimization. The challengers are aware of the need starting their feedback from the suitable timing and they intend to start the engine with only the feedforward. They would add some feedback methods to the feedforward. But nobody can succeed that at this moment.

The challenger D applied a data based approach to the air charge estimation. The result looks good. But, it is difficult to understand the physical background because their method is quite different from the ordinal one. We need the analysis why it is good and to be watching the progress. This method could provide the way to systematically enhance the knowledge to manage the control design. The engineers in the automotive industry would be heuristically working on the same purpose with many experiments.

The idea of the challengers $E$ is out of our intention. The other challengers try to keep the situation of "firing" but the challengers E actively use the condition of "misfiring". They give a stimulus to the industry. Their idea is connected with the variable cylinder number operation considered as a way to increase the fuel economy. Definitely, it is a way to suppress the engine speed overshoot. However, it has many issues not described here. However, they can be resolved by continuous efforts in the future.

\section{DISCUSSION}

All agreed that the engine model is complex. They observed hybrid features and the strong nonlinearity in the model equations. One said that no existing model based control theory can deal with such this complex system. It may be too early to let it be the final conclusion because control theories have contributed to the current prosperity of the automotive industry although almost all of the actual applications have such the complex feature. Thus, this type of the discussions is very important.

Many of the challengers try to get the useful information from the engine model. One way is to clarify the model equations and the other is to make a simple model from the simulation data numerically or the physical consideration. This is highly connected with "model simplification" that means the reduction of the system order and the number of parameters. It is obvious the structure identification is highly required for the purpose. It can be also obvious that the connection with physical considerations is effective.

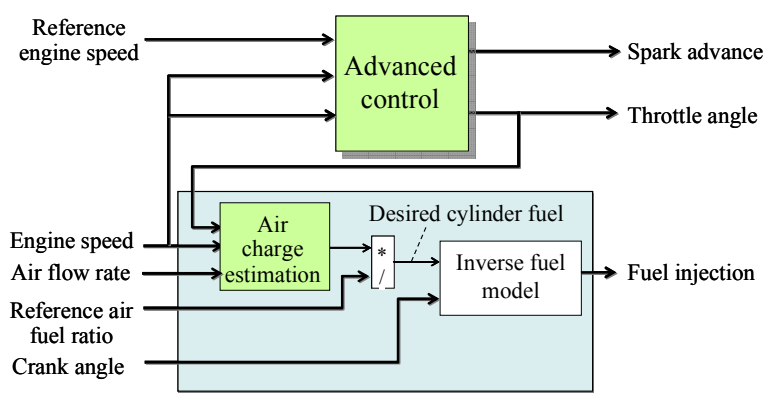

\section{Fig. 12 common architecture of succeeded control}

A key to succeed the control design seems to be the control architecture as shown in Fig. 12. The portion of the fuel injection control plays the role to keep the air fuel ratio ignitable. It is difficult to control the engine speed when the state transition between firing and misfiring happens. The challengers who could succeed starting the engine commonly used the architecture. Thus, it is obvious that the 
architecture makes the control problem easier at least. Once the fuel injection control is successfully developed, the control design of other portions can get relatively easy. Almost all are trying to know the optimum inputs time sequence profiles. Some took trial and error approaches and the others took numerical optimization methods. Even for the trial, the architecture is useful.

Quite a few of the challengers are looking into MPC (Model Predictive Control). One already considered an observer for the purpose and did a preliminary study of MPC. It may play an important role in this research activity.

Information theory and methods from computer science may be useful to attack the complex system although we didn't discuss what types of new method are possible.

A carefully worked-out plan is also essential. It is a natural way to encounter a complex problem. The requirements analysis may be the first step of the control design and the analysis of the model should be the second step. However, there are challengers who try to a specific control theory that may not cover all of the requirements before getting the results of the above steps. They will fail because we designed the benchmark problem not solved by such the way. They should make it clear first why it can fulfill the requirements. Actually, PI control of the throttle angle can regulate the engine speed at $650 \mathrm{rpm}$ although the response is not quick and it can't suppress the over shoot sufficiently. However, the advanced control without the required careful consideration may be worse than a PI control combined with other methods obviously fulfilling requirements. We think the combination of various methodologies is required for the benchmark problem and the optimization of the combination is not easy. The engineers in the automotive industry struggle to resolve such the kind of the problems.

From the above, we have to consider the purpose of advanced control. It may provide more accurate control, more robust control and more systematic control design than the existing control designs. It should be expected to cover more complex control design than before as well.

The committee will extend the activity period for one year expecting another challenger's participation. We are planning new problem for them. One idea of problem is a torque control for smooth driving when the automatic transmission is shifting. The engine model that has a new technology will be provided. The Variable Valve Lift technology that makes reducing the fuel consumption and quick torque response is launched in the market recently. Two engine model inputs that are the Variable Valve Lift and Variable Valve Timing will be increase. The redundancy of the inputs that controls the engine will increase further. We hope that a lot of groups challenge this new problem and show the various approaches and methodologies.

\section{CONCLUSIONS}

The SICE Research Committee on Advanced Powertrain Control Theory provides a V6 gasoline engine model and the control problem starting the engine. Seven challengers reported their intermediate results on September $6^{\text {th }}, 2007$ in the $36^{\text {th }}$ SICE Symposium on Control Theory. There would be more groups that are working on the engine model although we didn't get their results. Actually, there are groups that want to join this activity in the world. We feel that this activity is very useful for academic parties and the industry.

The problem is "complex" that means not to be solved by only an existing control methodology and requires the combination of methodologies. We are watching not only the control results but also the control design process.

Academic parties take various approaches and almost all already succeeded to start the engine but the overshoot of the engine speed still appears and the robustness is still problem. We can expect their progresses farther and hope to apply their controls to an actual engine installed at Sophia University.

\section{ACKNOWLEGEMENT}

CYBERNET SYSTEMS CO., LTD. provided

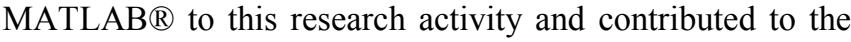
effort increasing the engine model execution speed. We would like to express our gratitude for their contributions.

\section{REFERENCES}

W. Blajer (1996), A Unified Approach to the Modeling of Holonomic and Nonholonomic Mechanical Systems, Mathematical Modeling of Systemes, 1996, Vol. 2, No.3, pp.157-174

A. Ohata, A. Sugiki,S. Suzuki and K. Furuta (2005), Engine Modelling Based on Projection Method and Conversation Laws, Preceding of CCA/ISIC/CACSD

Hendricks, E. and Sorenson, S. C. (1990), Mean Value Modeling of Spark Ignition Engines, SAE Technical Paper No. 900616.

Heywood, J. B. (1988), Internal Combustion Engine Fundamental, Mc-Graw Hill.

Abate, M. and V. Di Nunzio (1990), Idle Speed Control Using Optimal Regulation, SAE Technical Paper No.905008. 